\title{
Perception and practice of contraception among male soldiers in Sobi barracks, Ilorin, Nigeria
}

\author{
*Hussain NA ${ }^{1}$, Akande $\mathrm{TM}^{2}$, Osagbemi $\mathrm{GK}^{2}$, Olasupo ST${ }^{2}$, Salawu $\mathrm{KY}^{3}$, Adebayo $\mathrm{ET}^{4}$
}

1. Department of Preventive Health, Military Hospital, Lagos, Nigeria.

2. Department of Epidemiology and Community Health, University Teaching Hospital, Ilorin, Nigeria.

3. Department of Preventive Health, Military Hospital, Lagos, Nigeria.

4. Army Dental Centre, Military Hospital, Lagos, Nigeria

\begin{abstract}
Background: There is a popular belief among the general population that Nigerian soldiers tend to have large families but this has not been substantiated with evidence-based research. The Nigerian military health authority implements femaletargetted contraception strategies, with less focus on their husbands; who are the dominant fertility determinants.

Objective: To determine the perception and practice of contraception among male soldiers of Sobi Cantonment, Ilorin, Nigeria, with a view to instituting male-targeted contraceptive/family planning strategies.

Methodology: A cross-sectional survey of 334 male soldiers using multistage sampling technique and pre-tested interviewer administered questionnaires.

Results: The respondents' approval of contraception (73.6\%) and willingness to discuss it with their spouses/partners $(71.6 \%)$ were high. Fear of wives/partner's sexual promiscuity (55.7\%), cultural and religious beliefs $(43.2 \%)$, fear of the side effects of contraceptives $(29.5 \%)$ and the desire for more children (21.6\%) were reported reasons for the non-approval of contraception. The prevalence of contraceptive use among the respondents was low (12.3\%). There was a significant relationship between the respondents' educational level and contraceptive use $(\mathrm{p}<0.05)$.

Conclusion: The study revealed a high approval and willingness to discuss contraception with their spouses/partners but low contraceptive use.

Key words: Contraception, soldiers, male, perception, practice

African Health Sciences 2013; 13(2): 415 - 422 http://dx.doi.org/10.4314/ahs.v13i2.31
\end{abstract}

\section{Introduction}

The military population worldwide is a close-knit community whose reproductive pattern is prone to misrepresentation. In Nigeria, the contraceptive and family planning habits of the military population have been controversial with many civilians believing that military men have more children per family than the general population ${ }^{1}$. Although no surveys have established the link, prolonged separation from their families tempts military personnel to indulge in multiple sexual relationships; unmindful of the need for contraception and safe sex practice ${ }^{2}$. Soldiers who indulge in high alcohol consumption may have impaired sense of judgement and ability to observe contraceptive and safe sex. In conflict- ridden conditions, soldiers may take undue advantage of

\footnotetext{
*Corresponding author:

Dr N.A. Hussain

Department of Preventive Health, Military

Hospital

Lagos, Nigeria

Tel: +2348033921922

E-mail: naahussaini8968@yahoo.co.uk
}

their positions to have amorous relationship without any contraceptive measure ${ }^{3}$.

The centrality of men in reproductive issues and their passive involvement in population and family planning programmes have led to limited demographic impact of population programmes and policies ${ }^{4}$. But in the planning of contraception/ family planning programmes, the dominant role of men in the determination of fertility regulation and hence the family size is well established. Men are therefore categorized as "the forgotten $50 \%$ of family planning, ready to take part if only asked" 5 In Nigeria, the National Policy on Population recognises men as a special group that needs to be sensitised on their roles in family life ${ }^{6}$. Since men are the dominant decision-makers within the family and their reproductive preference and motivation influence the decision to reproduce, there is need to know the factors that influence men's desire for more children. More importantly, the active participation of men in fertility regulation is vital since they constitute an appreciable proportion of policy makers, administrators, politicians, religious and community leaders ${ }^{7,8,9}$. 
There is no doubt that the adverse effects of large family size on individuals, society and national development cannot be over emphasized. Within the military, it is not in doubt that large families could indirectly pose a great challenge to troop's combat readiness and efficiency. Mindful of this, Nigerian Army (NA) commanders at all levels have continuously expressed concern on the need for soldiers to have the number of children they can effectively cater for within the socio-economic status of their families. However, soldier's wives have been the main targets of the family planning intervention strategies with little focus on their husbands who take decisions on family issues. Thus, this survey aimed at determining the perception and practice of contraception among male soldiers with a view to obtaining baseline information and instituting appropriate male-targetted intervention measures.

\section{Methods}

\section{Study area}

This survey was conducted in Sobi Barracks of the Nigerian Army, Ilorin in North Central Nigeria. With a multi-ethnic/religious setting, the barracks has an approximate population of 1703 soldiers who use a 30-bed Medical Centre. The Medical Centre is adequately staffed to provide preventive (including family planning) and curative services. The centre also conducted weekly integrated health education on maternal and child health. In the various military units within the barracks, the soldiers were engaged in monthly durbars (meetings) and periodic "messing". These fora provided opportunities of close interaction and information sharing between the soldiers and their commanders. Soldiers as expressed in this study refer to both "the commissioned and non-commissioned officers". Specifically, commissioned officers are senior ranks while noncommissioned officers are junior.

\section{Sampling}

A multistage sampling technique was used to select three hundred and sixty soldiers for this study. This comprised an initial sampling proportionate to sizes of the three army units. Using each units' register as a sampling frame and a calculated sampling ratio, the required sample size in each unit was obtained by systematic sampling technique. The selection of the first respondent in each army unit was by simple random sampling and subsequent selections were based on the calculated sampling ratio for each army unit.
An informed consent was obtained from each of the selected participant. A total of 360 pretested interviewer-administered semi-structured questionnaires were administered to elicit the respondents' socio-demographic characteristics, perception and use of contraceptives. For the perception assessment, each correct reason given for the meaning of contraception was scored 1. "Full approval" of contraception was scored 2, "somehow approved" was scored 1 and "not approved" scored 0. Each correct reason given for approval of contraception, was scored 1. For contraceptive use, the proportion of respondents currently on contraceptives was determined. Ten research assistants were trained on administration of the questionnaires.

\section{Data collation and analysis}

The administered questionnaires were collated, validated and analysed using EPI Info 2002 computer software package. Frequency distribution and cross tabulation was done. Statistical level of significance was set at $\mathrm{p}<0.05$.

\section{Results}

Out of 360 questionnaires administered, $334(92.8 \%)$ were found suitable for statistical analysis. The respondents' age ranged between 18 and 60 years with a mean of $41.4 \pm 10.5$ years. About $85.3 \%$ of the respondents had at least secondary education; Christians constituted slightly over half $(53.0 \%)$ while $44.6 \%$ of the rest were muslims. More than 258 $(77.2 \%)$ of the total respondents were married while $66(19.8 \%)$ were single. Among the married respondents, $231(89.5 \%)$ had a monogamous relationship while $172(66.7 \%)$ married their first wife at less than 30 years old $($ mean $=27.5 \pm 4.6)$. About $89.5 \%$ of the respondents were Non-Commissioned Officers while the Commissioned Officers constituted $10.1 \%$ of the respondents. The demographics of the study population is shown in table 1.

Table 2 shows the perception of contraception by the respondents. On the meaning of contraception, $87(26 \%)$ of the total respondents said it was "prevention of pregnancy"; other meanings adduced were abortion (21.9\%), sexual abstinence $(37.4 \%)$ and preventing birth (14.7\%). Overall, two hundred and forty six $(73.6 \%)$ respondents approved of contraception while 88 $(26.4 \%)$ did not approve of it. Some of the reasons 
Table 1: Sociodemographic characteristics of respondents $(n=334)$

\begin{tabular}{|c|c|}
\hline Characteristics & Frequency $(\%)$ \\
\hline \multicolumn{2}{|l|}{ Age group (years) } \\
\hline $18-24$ & $20(6.0)$ \\
\hline $25-34$ & $73(21.9)$ \\
\hline $35-44$ & $102(30.5)$ \\
\hline $45-54$ & $94(28.1)$ \\
\hline$\geq 55$ & $45(13.5)$ \\
\hline \multicolumn{2}{|l|}{ Mean age $=41.4 \pm 10.5$} \\
\hline \multicolumn{2}{|l|}{ Educational Level } \\
\hline Primary & $49(14.7)$ \\
\hline Secondary & $233(69.8)$ \\
\hline Post secondary & $52(15.5)$ \\
\hline \multicolumn{2}{|l|}{ Religion } \\
\hline Chris tianity & $177(53.0)$ \\
\hline Islam & $149(44.6)$ \\
\hline Traditionalist & $8(2.4)$ \\
\hline \multicolumn{2}{|l|}{ Marital status } \\
\hline Single & $66(19.8)$ \\
\hline Married & $258(77.2)$ \\
\hline Divorced & $8(2.4)$ \\
\hline Separated & $2(0.6)$ \\
\hline \multicolumn{2}{|l|}{ Type of marriage $(n=258)$} \\
\hline Monogamy & $231(89.5)$ \\
\hline Polygamy & $27(10.5)$ \\
\hline \multicolumn{2}{|l|}{ Age at first marriage in years $(n=258)$} \\
\hline $18-24$ & $65(25.2)$ \\
\hline $25-29$ & $107(41.5)$ \\
\hline $30-34$ & $59(22.9)$ \\
\hline$\geq 35$ & $27(10.5)$ \\
\hline \multicolumn{2}{|l|}{ Mean $=27.5 \pm 4.6$} \\
\hline \multicolumn{2}{|l|}{ Rank } \\
\hline Junior non commissioned officers & $196(58.7)$ \\
\hline Senior non commissioned officers & $103(30.8)$ \\
\hline Commis sioned officer & $35(10.5)$ \\
\hline
\end{tabular}

reported for the approval of contraception included promotion of maternal health $(86.6 \%)$, allows adequate spacing of children (68.9\%), enables couples have desired number of children $(59.7 \%)$, allows sexual intercourse without pregnancy $(43.1 \%)$ and prevention of sexually transmitted infections $(32.1 \%)$. Encouragement of sexual promiscuity (55.7\%), religious and cultural beliefs $(43.2 \%)$, fear of the side effects of contraceptives $(29.5 \%)$ and desire for more children $(21.6 \%)$ were the reasons adduced for nonapproval of contraception. Two hundred and thirty nine $(71.6 \%)$ respondents approved of discussing contraception with their spouses or partners. The approval of contraception increased with educational qualification but this was not statistically significant (chi square $=2.26 ; \mathrm{p}>0.05)$. There was a statistically significant relationship between the respondents' educational qualification and use of contraceptives (chi square $=24.00 ; \mathrm{p}<0.05$ ); implying that the more educated, the more the likelihood of using contraceptives. 
Table 2: Respondents perception of contraception

\begin{tabular}{lc}
\hline Characteristics & Frequency (\%) \\
\hline Meaning of contraception & \\
Prevention of Pregnancy & $87(26.0)$ \\
Inducing abortion & $73(21.9)$ \\
Sexual abstinence & $125(37.4)$ \\
Preventing birth & $49(14.7)$ \\
Approval of contraception & \\
Fully approved & $219(65.5)$ \\
Somehow approved & $27(8.1)$ \\
Not approved & $88(26.4)$ \\
Reasons for approval of contraception (n=246) (multiple response) & \\
Promotes the health of mother & $213(86.6)$ \\
Adequate spacing of children & $169(68.9)$ \\
Enable couples have desired number of children & $147(59.7)$ \\
Prevents sexually transmitted diseases & $79(32.1)$ \\
Allows sexual intercourse without pregnancy & $106(43.1)$ \\
Reasons for non approval of contraception (n=88) (multiple response) & \\
Promotes wives / partner's sexual promiscuity & $43(48.9)$ \\
Cultural beliefs & $18(20.4)$ \\
Religious beliefs & $15(17.0)$ \\
Side effects of contraceptives & $26(29.5)$ \\
Desires for more children & $71(80.7)$ \\
Approval of contraceptive discussion with spouse or partner & \\
Yes & $239(71.6)$ \\
No & $95(28.4)$ \\
Currently use any contraceptive method & \\
Yes & $41(12.3)$ \\
No & $293(87.7)$ \\
\hline
\end{tabular}

Figure 1 showed that $41(12.3 \%)$ respondents (and their spouses) were on contraceptives during the period of this study. Male condoms $(56.1 \%)$, periodic abstinence $(9.8 \%)$ and spermicides $(14.6 \%)$ were the commonly used methods of contraception. Contraceptive pills $(9.8 \%)$, intra-uterine device $(4.9 \%)$ and injectable contraceptives $(2.5 \%)$ were also reportedly used by their spouses.

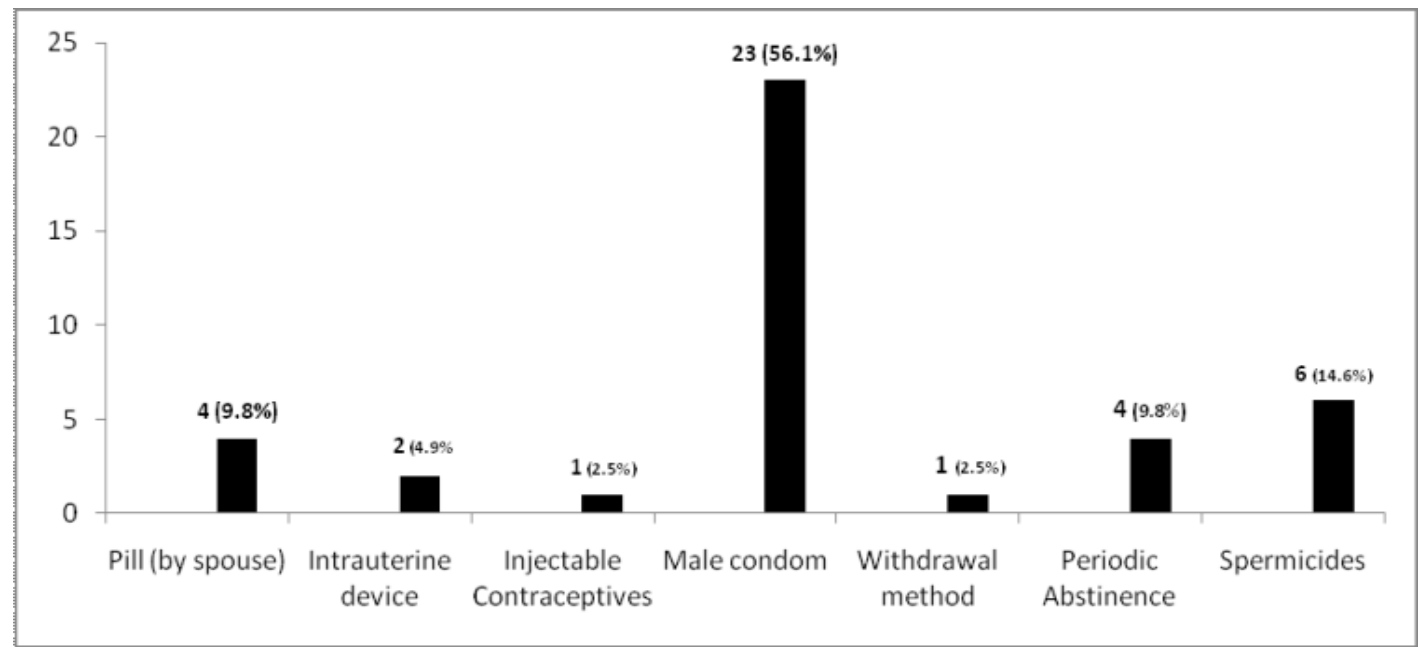

Figure 1: Contraceptive methods used by respondents and their spouses $(n=41)$ 
Table 3: Approval and current use of contraceptives by educational levels of respondents

\begin{tabular}{lccccc}
\hline Characteristics & \multicolumn{2}{c}{ Educational Level } & Total & p-value \\
\cline { 2 - 4 } & Primary & Secondary & Tertiary & & \\
\hline Approval of contraceptive & 36 & 176 & 34 & 246 & $\mathrm{X}^{2}=2.26 \mathrm{p}>0.05$ \\
Yes & 13 & 57 & 18 & 88 & \\
No & 13 & & & \\
Current use of contraception & 5 & 19 & 17 & 41 & $\mathrm{X}^{2}=24 \mathrm{p}<0.05$ \\
Yes & 44 & 214 & 35 & 293 & \\
No & & & & & \\
\hline
\end{tabular}

\section{Discussion}

Educating military personnel on the need to have a manageable family size within their socio-economic capacity is very vital and this can only be done if the factors that promote or militate against contraception in their setting are identified. In this study, the respondents' age range of 18 to 54 years reflects a sexually active age group that desires contraception/ family planning. Of the over three-quarter $(77.2 \%)$ married respondents, more than two-third (69.2\%) had monogamous relationship while the mean age at first marriage was 27.5 years. There was a high approval of contraception and willingness to discuss it with their spouses and partners. The adduced reasons for non-approval of contraception were “encouraging wives/partner's sexual promiscuity, cultural/religious beliefs, fear of the side effects of contraceptives and the desire for more children". The contraceptive use among the respondents was low $(12.3 \%)$ and there was a statistically significant relationship between the respondents' educational level and contraceptive use.

Sexual exposure at younger age is often associated with high fecundity and in Akande's study ${ }^{10}$, males in North Central Nigeria frequently married early. Although, low educational background and religion were identified factors for this, they may not be applicable to this study population with high educational level and multi-ethnic/cultural setting. Frequent redeployment and perceived high vulnerability to injuries/death from military services (which could necessitate the dire need to have children early) could be the reasons for early marriage among these respondents. The high monogamy could have been influenced by the respondents' religion (since Christianity encourages monogamy) and high educational background; both being important predictive indices of marital union and ultimate influence on contraception and family planning ${ }^{11}$.
Correct appreciation and interpretation of contraception is essential to the respondent's perception and practice. In this study, about onequarter $(26 \%)$ respondents perceived contraception correctly as the "prevention of pregnancy" while about three-quarter $(74 \%)$ respondents perceived it as either "abortion", or "sexual abstinence", or "preventing birth". This misinterpretation is similar to a previous study where contraception was termed an "anti-child, anti-family and anti-life"" . Thus, in formulating an intervention strategy for this study population, the emphasis should be on contraception as a means of "preventing pregnancy" rather than it being "abortion" or "anti-child".

Approval and willingness to advocate contraceptive methods and practice are important perception variables. In this study, almost threequarter of respondents approved of contraception, corroborating a survey from the Republic of Sudan where over $80 \%$ of the respondents' revealed favourable attitudes with husbands willing to support their wives practice of contraception ${ }^{13}$. Promotion of maternal health, adequate child spacing, prevention of sexually transmitted infections and sex without pregnancy were the common reasons for approval of contraception by the respondents. These reasons are similar to those in previous studies ${ }^{14,15}$.

In contrast, 88 (26.4\%) respondents did not approve of contraception for reasons such as desire for more children, that it encourages sexual promiscuity, religious/cultural beliefs and the fear of the side effects of the contraceptives. Although these similar reasons were reported for non-approval of contraception in some studies ${ }^{16,17,18}$, the desire for more children (particularly sons) has been identified as a significant factor in the negative attitude to contraception. In many African societies, males are valued more highly than females and therefore couples tend to aim for the birth and survival of at least a son ${ }^{19,20}$. This is particularly pronounced in the 
traditional societies where sons are needed to maintain the family lineage, assist the family economically and provide parents with social security in old age $\mathrm{e}^{21,22,23}$. This implies that receptivity to contraception and willingness to use contraceptives could be influenced by the number of living sons a couple has. Bearing this in mind, it is necessary to plan and implement strategies that will focus on allaying the fear of contraceptive use, show the advantages of having a manageable family size, gender equality and involvement of religious leaders and military commanders.

In discussing contraception, it is vital to have a better understanding of the fertility decision-making process and the relative influence husbands and wives have over one another. In this study, majority $(71.6 \%)$ respondents' approved of discussing contraception with their spouses or partners. Previous studies have identified lack of effective couple communication, segregated conjugal role relationship and maledominated decision-making as significant predictors of non-use of contraception ${ }^{24,25,26,27,28}$. Also, the impact of social support and spousal communication were identified as important predictors of contraceptive use ${ }^{29}$.

The prevalence of contraceptive use among the study respondents (and their spouses) was 12.3\%. This figure is below Nigeria's current contraceptive prevalence rate of $15.0 \%$ (for all methods) but is similar to the finding in Akande et $\mathrm{al}^{10}$. The low contraceptive use could probably be attributed to the fact that the respondents may not be aware that their wives are using contraceptives since it is not unusual in Nigeria for women to use contraceptives without consent from their husbands ${ }^{1}$. Condoms, periodic abstinence and coitus interruptus (withdrawal method) were the most commonly used contraceptive methods among the males. No significant use of the hormonal contraceptives by their spouses/partners was observed. This may be attributed to the fear of the side effects of hormonal contraceptives. This finding corroborates a Ghanaian study, where $50 \%$ of the male acceptors preferred condoms, 34\% preferred the foam (spermicides) while $11 \%$ favoured the pill (for their spouses) $)^{30,31}$.

Education could have a far-reaching impact on the family life and family size preference of men. Thus this study determined the relationship between the respondents' educational levels, approval of contraception and contraceptive use. The result showed a positive but statistically insignificant relationship between their educational level and approval of contraception [chi square $=2.26$, $\mathrm{p}>0.05]$. However, there was a statistically significant relationship between the respondents' educational level and contraceptive use [chi square $=24, \mathrm{p}<0.05$ ] and this finding corroborates previous studies ${ }^{9,11,25,26}$. Couple's education contributes to reducing infant and child mortality and therefore reducing fertility; since educated couples no longer feel the need to have additional children as an insurance against child death ${ }^{31,32,33}$. The discrepancy between the high approval of contraception and low contraceptive use could be attributed to some sociocultural factors that need to be further researched. However, appropriate intervention strategies that focus on continuous contraception/family planning education, increased gender equality, enhancement of contraceptive uptake by both males and females and involvement of religious leaders and military commanders would facilitate the use of contraceptives among these respondents.

\section{Conclusion}

The study showed that male Nigerian soldiers have high approval and willingness to discuss contraception with their spouses and partners but their low contraceptive use did not match this favourable disposition. To bridge this gap, there is need to design appropriate intervention strategies with involvement of religious leaders and military commanders.

\section{Recommendation}

It is recommended that a continuous male-targetted contraception programme be established among soldiers.

\section{Acknowledgements}

The contributions and support by the Commanding Officer and staff of Sobi Barracks Medical Centre is acknowledged.

\section{References}

1. Akande TM. Health Education and Contraceptive use among soldiers wives at Sobi Barracks, Ilorin. A dissertation submitted to the National Postgraduate Medical College of Nigeria, for the award of the Fellow of the Medical College of Public Health (FMCPH). 1994.

2. Joint United Nations Programme on HIV/ AIDS/World Health Organisation. AIDS epidemic update. December 2002; Geneva UNAIDS.

African Health Sciences Vol 13 Issue 2 June 2013 
3. Okulate GT, Osibogun A, Obe J. HIV/AIDS fear knowledge and alcohol use in a Military population. The Cliniscope, Journal of Military Hospital, Lagos, Nigeria. 2001; 1(3): 14-19.

4. Caldwell JC, Caldwell P. The Culture context of high fertility in sub-Saharan Africa. Population and Development Review. 1987; 13: 409-437.

5. Finger WR. Getting more men involved. Network Family Health International.1992; 13(1): 4-6.

6. Federal Ministry of Health and Social Services. National Policy on population for development, Federal Republic of Nigeria. Federal Ministry of Health and Social Services, Ikoyi, Lagos, Nigeria. 1988: 19-20.

7. Magrani RJ, Betrand JT, Makahi B, McDonald SW. Men, Marriage and Fatherhood in Kinshasha, Zaire. International Family Planning Perspectives. 1995; 21(1): 19-25.

8. Obionu CN. Family Planning knowledge, attitude and practice among males in a Nigerian urban population. East African Medical Journal. March 1998; 75(3): 131-134.

9. Muvandi I. Fertility behaviour and contraceptive use in Kenya; Findings from a male survey. African Journal of Fertility, Sexuality and Reproductive Health. 1996; 1 (2): 136-145.

10. Akande T, Abegunde D, Petu A. The role of men in Family planning in Kwara and Kogi states, Nigeria. Population Research Fund Management Unit. Nigerian Institute of Social and Economic Research (NISER). Ibadan, Nigeria 1998; 1-63.

11. Isiugo-Abanihe VC. The Reproductive motivation and Family size preference among Nigerian Men. Studies in Family Planning. 1994, 25(3); 149-160.

12. Marcelino AB. Combating opposition in the Philippines. Planned Parenthood Challenges. 1996(1):28-30.

13. Khalifa MA. Attitudes of urban Sudanese Men toward Family Planning. Studies in family planning. 1988; 19(4): 236-243.

14. Awoyemi AO, Osagbemi GK, Koledade I. Knowledge, attitude and practice of Family planning among religious and community leaders in Ilorin, Nigeria. Nigerian Medical Journal. August 2001, 4(1); 4-8.

15. Mcginn T, Bamba A, Bama M. Male knowledge, use and attitudes regarding Family Planning in Burkina Faso. International Family Planning Perspectives. Sept 1989; 15(3):84-87.

African Health Sciences Vol 13 Issue 2 June 2013
16. Obisesan KA, Adeyemo AA, Ohaeri JV, Aramide FA, Okafor SI. The Family planning aspects of the practice of traditional healers in Ibadan, Nigeria. West African Journal of Medicine. July-Sept.1997, 16(3)184-190.

17. Adamchak DJ, Mbizuo M. Family Planning Knowledge, Attitude and Practice of Males in Zimbabwe. Studies in Family Planning. Jan./Feb. 1991; 22(1):31-38.

18. Akinfeleye R, Charles JO, Omideyi AK, Feyisetan B. Sociocultural factors affecting Attitude and Behaviour regarding Population and family life issues in Nigeria. United Nations Population Fund (UNFPA). 1994; 1-125.

19. Ghazal-Aswad S. A study on the Knowledge and Practice of Contraception among Men in United Arab Emirates. Journal of Family Planning and Reproductive Health Care. 2002; 28(4): 196-200.

20. Karin Ringheim. Factors that determine the prevalence of use of contraceptive methods for Men. Studies in Family Planning. 1993; 24(1): 8799.

21. Oni GA, McCarthy M. Family planning knowledge, attitudes and practices of males in Ilorin, Nigeria. International Family Planning Perspectives. June 1991; 17(2):50-54.

22. Oyeka IC. Influence of the Number of living sons on contraceptive use among female teachers in Nigeria. Studies in Family Planning. 1989, 20(3): 170-174.

23. Gadallah S, McCarthy J, Campbell O. How the number of living sons influence contraceptive use in Menocifia Governate, Egypt. Studies in Family Planning. May/June 1985; 16(3):166-169.

24. Ezeh AC. The influence of spouse over each other Contraceptive attitude in Ghana. Studies in Family Planning. May/June 1993, 24(3): 163-73.

25. Kannae L, Peddleton BF. Socio-economic status and use of Family planning among Ghanaian government Workers. Social Biology. 1998 45(1): 113-133.

26. Odimegwu CO. Family planning attitudes and use in Nigeria; a Factor analysis. International Family Planning Perspectives. June 1999; 25(2): 8691.

27. Mustafa MAB, Mumford SO. Male attitudes towards Family planning in Khartoum, Sudan. Journal of Biosocial Sciences. 1984, 16; 437-439.

28. Hamouda A. Contraceptive use, Family differentials and Family planning issues in Jordan. Paper presented at the symposium on Jordan husband fertility survey. Aman-Jordan. $4^{\text {th }}$ June 1987. 
29. Osagbemi GK, Oyeyipo AA, Olu OO. Role of men in Family planning in Niger and Oyo States. Population Research Fund. Nigerian Institute of Social and Economic Research (NISER). 1998; 158.

30. Ezeh AC. Contraceptive Practice in Ghana; does Partners Attitude matter? A paper presented at the annual conference of the Population Association of America. Denver. Colorado. 29 ${ }^{\text {th }}$ April $-2^{\text {nd }}$ May 1992.

31. Lamptey P, Nicholes DD, Ofosu-Amaah S, Lourie IM. An Evaluation of male contraceptives in rural Ghana. Studies in Family Planning. 1978; 8:222-225.

32. Ronald Freedom. The contribution of Social sciences research to Population policy and Family planning Programme effectiveness. Studies in Family Planning. 1987; 18(2): 57-79.

33. Adedimeji BA. Women's Reproductive Health, Empowerment and Male Involvement: Findings from Seven States of Nigeria. Association of Reproductive and Family Health (ARFH). 1998. Monograph Series No.1; 1-40 